\title{
Impact of the Georgia Charitable Care Network on cost savings from lowering blood pressure and decreasing emergency department use
}

\author{
Phaedra Corso, $\mathrm{PhD}^{1}$, Rebecca Walcott, $\mathrm{MPH}^{1}$, Justin Ingels, $\mathrm{MPH}^{1}$ \\ ${ }^{1}$ Economic Evaluation Research Group, College of Public Health, University of Georgia, Athens, GA
}

\begin{abstract}
Background: The Georgia Charitable Care Network (GCCN) is a non-profit organization whose primary mission is to foster collaborative partnerships to deliver compassionate health care to low-income, uninsured individuals. Hypertension screening and management is a service provide by $90+$ clinics in the GCCN statewide.

Methods: With data from $\mathrm{N}=1661$ patients who were screened and treated for hypertension at $\mathrm{n}=12$ clinics in 2013 , the impact of hypertension management on blood pressure levels, the incidence of coronary heart disease (CHD) and stroke, and utilization of emergency departments (EDs) were examined. The resulting changes in healthcare utilization were converted to changes in healthcare costs and compared to the expenditures for clinics providing screening and treatment services to the same population over a one-year period.
\end{abstract}

Results: Patients with an initial diagnosis of hypertension or prehypertension experienced average reductions of $10.27 \mathrm{mmHg}$ and $6.32 \mathrm{mmHg}$ in systolic and diastolic blood pressure, respectively, during their follow-up visits. These changes were associated with $32.0 \%$ and $44.3 \%$ reductions in the relative risk of CHD and stroke, respectively. The savings from this reduction in blood pressure and avoided ED visits for 1661 hypertensive patients produced positive net benefits in 2013 US\$, of more than $\$ 400,000$, with a benefit-cost ratio of 1.6 .

Conclusions: For every dollar invested in GCCN clinics for hypertension screening and management, there is a benefit to the healthcare system through reduced costs of \$1.60. GCCN clinics are a cost-saving delivery model for underserved communities with poor health status and high ED usage.

Keywords: hypertension, cost(s), benefit-cost analysis, return on investment, charitable care

\section{INTRODUCTION}

Charitable clinics have long worked at the local level to address needs of the uninsured through a wide range of free and nearly free primary healthcare services, often with the goal to prevent and manage disease before patients require emergency care or are hospitalized. These clinics deliver a variety of services, including primary, preventive, and specialty care, and provide an important safety net for lowincome, uninsured, and underserved populations in both rural and urban communities. In Georgia, there are more than 100 independent, not-for-profit charitable clinics and hundreds of physicians, dentists, and other health care professionals who provide charitable care throughout the state. Each is dedicated to serving, through the GCCN, many of the more than 1.8 million uninsured in Georgia (Smith \& Medalia, 2014).

At the federal level, the Affordable Care Act (ACA) was passed, in part, to address the needs of the uninsured through Medicaid expansion and federal health insurance subsidies for individuals below $400 \%$ of the poverty line.
Despite these efforts, it has been estimated that 20 million individuals will remain uninsured after the ACA is fully implemented (Chazin et al, 2010). In Georgia, where the political leadership has decided to forego Medicaid expansion, hundreds of thousands of citizens remain uninsured, at a rate considerably higher than the national average (Georgia Budget Policy Institute, 2015). Therefore, clinics within GCCN will continue to be essential providers of healthcare access to Georgia's vulnerable populations.

A fundamental challenge faced by charitable clinics is to demonstrate to funders that they have a clinical and economic impact within their communities. Clinics often lack the resources to collect patient outcome data over time and the expertise to assess economic return on investment. Because nonprofit organizations serving the under- and uninsured have limited resources with which to deliver the costly care associated with populations encountering barriers to access (Bicki et al, 2013), it is necessary for these health care clinics to understand and empirically evaluate the economic impact of effectively delivering primary care to their clinic population. Funders of these organizations, 
such as local businesses and/or hospitals serving the same community, may also ask for (or require) information on how their resources are spent and the economic returns for those resources expended. In this study, longitudinal data provided by clinics were used to assess the economic impact of treating and managing patients in the GCCN.

\section{GCCN Clinics}

GCCN member clinics include both charitable and free clinics, and the network is diverse in terms of size, model, and scope of services provided. Charitable clinics are notfor-profit, community-based health centers that provide services to uninsured, underserved, and vulnerable populations. Most offer preventive services and fund their operations through grants, patient fees, and donations. Although charitable clinics may serve the publicly insured, they do not receive enhanced reimbursements from Medicaid. Patients may pay a flat rate or a fee based on a sliding scale. Free clinics represent $63 \%$ of all GCCN clinics and provide healthcare services at no cost to patients. These clinics utilize a volunteer/staff model and provide a range of medical, dental, pharmacy, optical, and behavioral health services to economically disadvantaged individuals. Free clinics restrict eligibility to the uninsured or individuals with limited access to primary care, specialty care, or pharmaceuticals. These clinics are often communitysupported and are funded primarily by private donations and foundations. Most personnel at charitable and free clinics are volunteers, including physicians, dentists, and other specialty providers from private practices and hospitals.

GCCN clinics, located in 90 of Georgia's 159 counties, provide various healthcare services: $46 \%$ provide dental or vision services; $86 \%$ provide prescription assistance; $83 \%$ provide health education; and $34 \%$ provide mental health services. On average, clinics are open 20 hours per week and receive 4200 hours of volunteer labor each year. Most of the population served by GCCN clinics can be characterized as the sick and the working poor. Most patients are employed, and $80 \%$ have one or more chronic illness requiring extensive and ongoing medical treatment, coordination of care, and patient education.

Since hypertension is the most common diagnosis for patients served by GCCN clinics, this study focuses on the cost-savings to the healthcare system for the identification, treatment, and management of hypertension. To our knowledge, this is the first economic evaluation to assess the cost-savings from lowering blood pressure and reducing emergency department (ED) usage through the treatment of hypertensive patients in a free clinic setting.

\section{METHODS}

Study Sample

Participating GCCN clinics $(n=95)$ were contacted and access to the following data was requested for the 2013 calendar year: a) annual operating expenditures; b) number of unique patients served annually; c) number of patient visits annually; d) number of hypertension screenings performed; and e) for newly diagnosed hypertensive patients, blood pressure at the time of screening and at a 1year follow-up. Eight clinics were excluded, as they were not in operation for the entire year of 2013. Data on the number of patients served and/or the number of patient visits were received from $n=53$ clinics, or $61 \%$ of the network. Annual operating costs or costs per visit were obtained for $\mathrm{n}=18$ clinics $(21 \%)$; and data specific to hypertension management was received from $n=12$ clinics (14\%). Locations of the clinics that provided detailed patient-level data on hypertension management are shown in Figure 1. They represent 12 of the 18 public health districts across the state of Georgia. The clinics include: Bethesda Community Clinic in Cherokee County, the Free Clinic of Rome in Floyd County; Good News Clinics in Hall County; Good Shepherd Clinic in Clayton County; Macon Volunteer Clinic in Bibb County; Partnership Health Center in Lowndes County; Physicians' Care Clinic in DeKalb County; Rock Springs Clinic in Lamar County; The Care Place in Douglas County; Mercy Medical Clinic in Toombs County; Gwinnett Community Clinic in Gwinnett County; and the Athens Nurses Clinic in Clarke County.

\section{Figure 1. Location of clinics providing data on HTN patients}

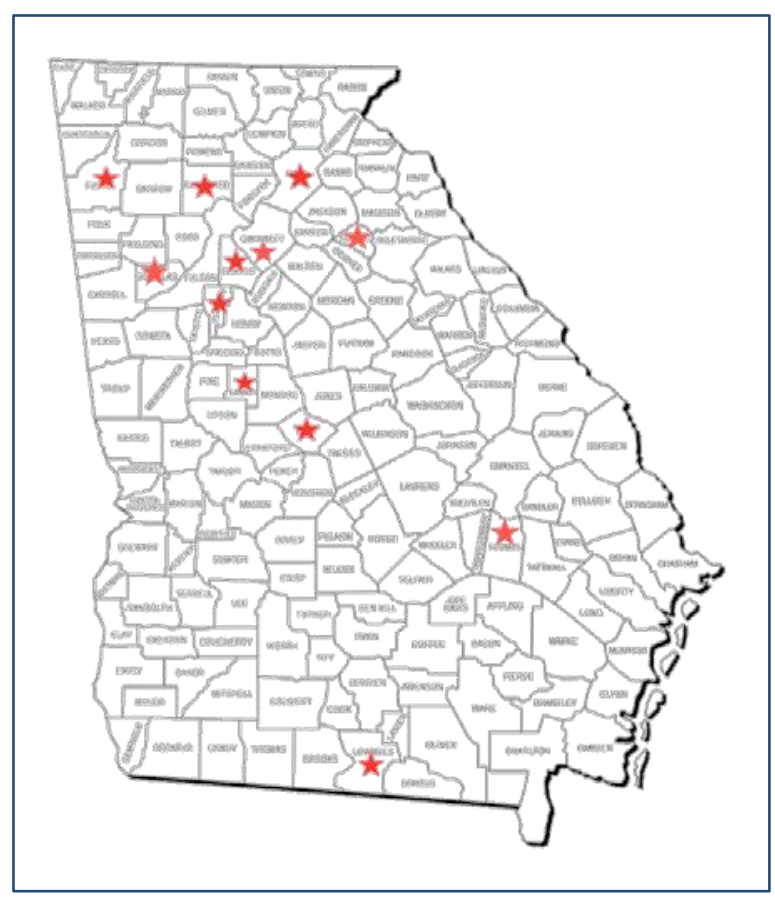


Table 1 provides descriptive statistics from all participating clinics, and Table 2 provides descriptive statistics for the $\mathrm{n}=1661$ hypertensive patients visiting the 12 GCCN clinics.

\section{Table 1. Descriptive Statistics of Data Received from Clinics}

\begin{tabular}{|ccccc|}
\hline \# of Clinics & $\begin{array}{c}\text { \# of Patients in 2013 } \\
\text { (range) }\end{array}$ & $\begin{array}{c}\text { \# of Patient Visits in } \\
\mathbf{2 0 1 3} \\
\text { (range) }\end{array}$ & $\begin{array}{c}\text { 2013 Operating Costs } \\
\text { (range) }\end{array}$ & $\begin{array}{c}\text { 2013 Costs/Visit } \\
\text { (range) }\end{array}$ \\
\hline \multirow{4}{*}{ Mean: 2114 } & & & \\
& Median: 782 & & & \\
& $(128-12502)$ & Mean: 6847 & & \\
50 & Median: 4123 & & \\
& $(306-32122)$ & Mean: 438,971 & Mean: 88 \\
& & Median: 283,429 & Median: 70 \\
& & $(41523-2.9$ million) & $(9.37-313.90)$ \\
\hline
\end{tabular}

\section{Table 2. Descriptive Statistics for the Hypertensive Patients from N=12 Clinics}

\begin{tabular}{|c|c|c|c|c|c|}
\hline \multirow{2}{*}{$\begin{array}{c}\text { \# of Hypertension } \\
\text { Patients }\end{array}$} & $\begin{array}{c}\text { \# of Hypertension } \\
\text { Visits/Year (from n=4 } \\
\text { clinics only) }\end{array}$ & Systolic & Diastolic & Systolic & Diastolic \\
\cline { 3 - 6 } & Mean: 5.5 & & & & 84.49 \\
\hline Mean: 138.42 & Median: 5 & 147.9 & 90.8 & 137.71 & \\
\hline Range: $49-283$ & Range: 2-25 & & & & \\
\hline Total: 1661 patients & & & & & \\
\hline
\end{tabular}

The perspective of this analysis was that of the healthcare system; that is, expenditures and avoided costs were those accrued by the healthcare system only (regardless of payer). The study period was one year, making discounting of costs unnecessary. All costs were inflated to 2013 US dollars using the medical component of the consumer price index (US Department of Labor, 2014).

\section{Analysis of Coronary Heart Disease (CHD) and Stroke Events and Costs Averted \\ Following the methodology outlined by Song et al. (2013),} who estimated the cost savings of hypertension screening in mobile clinics, the reductions in the risk of CHD events and stroke that result from reductions in blood pressure were examined. To determine the incidence of a CHD event in Georgia for a hypertensive patient, rates from Georgia's Online Analytic Statistical Information System (OASIS) database (Georgia Department of Public Health, 2015) were used for diagnoses of high blood pressure, hypertensive heart disease, obstructive heart disease including heart attack, and aortic aneurism. As a proxy for CHD incidence, because these data were not available otherwise, the 2013 annual hospital discharge rates and death rates for the aforementioned diagnoses were summed, resulting in an estimate of 7.9 cases of CHD per 1000 person-years for ages 50-59 years, including all races and genders. Song et al. (2013) used a CHD incidence of 11.4 per 1000 personyears, which was incorporated into the sensitivity analysis.
Because the OASIS database does not differentiate by type of stroke, both ischemic and hemorrhagic events were included in the definition of stroke, as did Song et al. (2013). For a baseline annual incidence of stroke, 3.2 per 1000 person-years was used, which is equal to the 2013 rate of hospital discharges and deaths for stroke in persons aged 50-59, including all races and genders. This estimate is similar to other estimates used previously, including that by Song et al. (2013), which was 3.3 per 1000 person-years.

To estimate the proportion of CHD and stroke events that could be prevented with management of hypertension, the results of a meta-analysis by Law et al. (2009), which were also incorporated into the study by Song et al. (2013), were used. The regression coefficients for the meta-analysis were based on studies of blood pressure measured at baseline with a minimum follow-up of 6 months. Data on blood pressure change are from the sample of $n=1661$ patients at the 12 clinics (Table 2). Following Song et al. (2013), these reductions should have been adjusted for age, race, sex, and comorbidity status. However, we used unadjusted estimates, as these patient-level attributes were not available for this sample. With the equations below, the relative risk reductions for $\mathrm{CHD}$ and stroke events resulting from hypertension management and treatment were estimated. These risk reductions were then applied to the clinic population to estimate the number of CHD and stroke events averted. 


\section{CHD Events}

Relative Risk Reduction SYSTOLIC $=1-.5^{\text {Systolic } \Delta / 20}$
Relative Risk Reduction
DIASTOLIC $=1-.52^{\text {Diastolic } / 10}$

$\underline{\text { Stroke Events }}$

Relative Risk Reduction SYSTOLIC $=1-.38^{\text {Systolic } / 20}$

Relative Risk Reduction DIASTOLIC $=1-.34^{\text {Diastolic } \Delta / 10}$

To apply unit costs to CHD and stroke events averted, estimates from the Coronary Heart Disease Policy Model were used. This is a validated model that has been used for over two decades to assess effects and costs of different CHD prevention and treatment strategies (Moran et al., 2015; Weinstein et al., 1987). For each CHD event, the costs of fatal and not-fatal hospitalizations from acute myocardial infarction plus 1-year follow-up costs $(\$ 44,000$ for non-fatal and $\$ 46,000$ for fatal, in 2010 US\$) were used. These costs were inflated to 2013 US $\$$ and weighted to reflect the data on incidence of fatal and not-fatal CHD events from Georgia's OASIS data $(14 \%$ and $86 \%$, respectively), yielding a final estimate of $\$ 53,377$. For each stroke event, hospitalization and one-year follow-up costs for fatal and not-fatal strokes $(\$ 37,000$ for non-fatal stroke and $\$ 26,000$ for fatal strokes, in 2010 US\$) were used. These costs were weighted to reflect the data on incidence of fatal and not-fatal strokes from Georgia's OASIS data (8\% and 92\%, respectively), thus equaling \$39,437 (2013 US\$).

\section{Analysis of ED Utilization and Costs Averted}

Following the methodology of Song et al. (2013), how GCCN hypertension management reduced ED utilization and costs was also considered. Following Bicki et al. (2012), the assumption was that $49 \%$, or $n=814$, of the initial hypertension visits resulted in an avoided ED visit. For the sensitivity analysis, the assumption was that the best-case scenario would be that $78 \%$ of first-time clinic visits resulted in an avoided ED visit, based on a small study conducted in the Athens Nurses Clinic (personal communication, August 26, 2015). In the worst-case scenario, $34.5 \%$ of first-time ED visits were assumed to be averted (Nadkarni \& Philbrick, 2003). For the unit cost of an ED visit, \$951 was used. This was derived from data of the Agency for Healthcare Research and Quality, 2008 Medical Expenditure Panel Survey showing expenditures for an ED visit with no surgery $=\$ 821$ (in 2008\$) inflated to 2013\$ (Machlin \& Chowdhury, 2011). For the worstcase scenario, $\$ 413$ was used, the reported cost of an ED visit for a sore throat and flu symptoms at Athens Regional Medical Center, where a $40 \%$ discount was applied for being uninsured (Georgia Health News, 2013).

\section{Estimating Cost-Savings}

Cost-savings were estimated by first summing the savings associated with reduced $\mathrm{CHD}$ and stroke events and reductions in ED utilization and then comparing these savings to the GCCN expenditures for treating hypertensive patients. From the data collected (Table 2), each hypertension patient was estimated to have visited the clinic on average 5.5 times in the year. The average cost for a GCCN visit, as estimated in Table 1 , was $\$ 88$. However, because this mean was influenced by outliers, we eliminated all cost per visit values that were +/- 3 standard deviation points from the mean, thus eliminating $\mathrm{n}=1$ cost per clinic value (\$314/visit). The adjusted mean was $\$ 75$ per visit.

The cost-savings summary measures included are common in the field of economic evaluation, including net-benefits (NBs), the benefit-cost (BC) ratio, and return on investment (ROI) (Haddix et al., 2003). NBs are calculated by subtracting expenditures of a program from an estimate of its monetary benefits or savings. An NB result $>0$ suggests that there is an economic rationale for funding a program. $\mathrm{BC}$ ratios are calculated by dividing a program's benefits or savings by its expenditures. A BC ratio $>1$ suggests that there is an economic rationale for funding a program. Finally, ROI is calculated by dividing a program's estimate of NB by its expenditures. Like the NB measure, an ROI $>0$ reflects an economic incentive for funding a program.

\section{RESULTS}

For the 1661 patients in the sample, the reductions in systolic and diastolic blood pressure were associated with a $32.0 \%$ reduction in CHD events and a $44.3 \%$ reduction in strokes. Using the unit cost per case averted, the reduction in incidence was estimated to save $\$ 318,832$ from blood pressure reductions over the one-year study period for the 1661 hypertensive patients in the sample (Table 3).

With each avoidable ED visit costing an average of \$951, there was an estimated total savings of $\$ 774,114$ from the 814 estimated ED visits avoided for the sample of 1661 patients. This means that, for every 100 patients who visit a GCCN clinic annually, the healthcare system saves more than $\$ 50,000$ in avoided $E D$ visits.

In 2013, GCCN savings were $\$ 1,092,946$ for the sample of 1661 hypertension patients; GCCN expenditures for treating these patients in the same period were $\$ 685,163$ (Table 3). The NBs were $\$ 407,783$ and the BC ratio was 1.6 (Table 3 ). The ROI calculation was slightly different in that it compared NB divided by expenditures. For these results, the ROI was 0.6 , or a $60 \%$ return on investment.

With a sensitivity analysis, savings, expenditures, and costsavings for a best-case and worst-case scenario were estimated. For the best-case scenario, all parameter estimates in favor of GCCN, where available, were used; in the worst-case scenario, all estimates against GCCN, where available, were used. In the best-case scenario, benefits exceeded costs by more than $\$ 1$ million, and the ratio of benefits to costs was 2.9 (Table 3 ). These results imply that, for each $\$ 1$ spent in the best-case scenario, savings were $\$ 2.90$, representing a $190 \%$ return on investment. In the worst-case scenario, benefits did not exceed costs, and for each $\$ 1$ spent, savings were only $\$ 0.63$, representing a $37 \%$ loss on investment. However, these losses occurred only when both ED visits avoided and ED unit costs were at their 
lowest estimates. When the percent of ED visits avoided was varied (from $34.5 \%$ to $78 \%$ ) without varying any other parameter, the $\mathrm{BC}$ ratio rose to a favorable range of 1.26 to
2.26. When the cost of an ED visit was varied without varying any other parameter, any ED unit cost $>\$ 450$ resulted in a positive NB.

\section{Table 3. Calculation of Return on Investment in the GCCN}

\begin{tabular}{|c|c|c|c|}
\hline Category & Baseline & Best Case & Worst Case \\
\hline \multicolumn{4}{|l|}{ Blood Pressure Reduction } \\
\hline \multicolumn{4}{|l|}{ CHD Avoided } \\
\hline Baseline annual incidence (per 1000) & 7.9 & 11.4 & \\
\hline Preventable fraction (percent) & 32 & & \\
\hline $\begin{array}{l}\text { CHD cases avoided for the sample } \\
(n=1661)\end{array}$ & 4.2 & 6 & \\
\hline Total CHD cost per case & $\$ 53,377$ & & \\
\hline Total CHD costs avoided & $\$ 224,183$ & $\$ 320,262$ & \\
\hline \multicolumn{4}{|l|}{ Stroke Avoided } \\
\hline Baseline annual incidence (per 1000) & 3.2 & & \\
\hline Preventable fraction (percent) & 44.3 & & \\
\hline $\begin{array}{l}\text { Stroke cases avoided for the sample } \\
(\mathrm{n}=1661)\end{array}$ & 2.4 & & \\
\hline Total stroke cost per case for 1-year follow-up & $\$ 39,437$ & & \\
\hline Total stroke costs avoided & $\$ 94,649$ & & \\
\hline Total Savings from BP Reduction & $\$ 318,832$ & $\$ 414,911$ & \\
\hline \multicolumn{4}{|l|}{ ED Visits Avoided } \\
\hline $\begin{array}{l}\text { Hypertension visits resulting in an avoided ED } \\
\text { visit (percent) }\end{array}$ & 49 & 78 & 34.5 \\
\hline $\begin{array}{l}\text { \# of initial hypertension visits to the ED that } \\
\text { would have occurred if not for the GCCN } \\
\text { (for } n=1661 \text { ) }\end{array}$ & 814 & 1296 & 573 \\
\hline Cost per avoidable ED visit & $\$ 951$ & & $\$ 413$ \\
\hline Total Savings from ED Visits Avoided & $\$ 774,114$ & $\$ 1,232,496$ & $\$ 236,649$ \\
\hline TOTAL SAVINGS & $\$ 1,092,946$ & $\$ 1,647,407$ & $\$ 555,481$ \\
\hline \multicolumn{4}{|l|}{ GCCN Expenditures } \\
\hline \# of hypertension visits per year & 5.5 & 5 & 6 \\
\hline $\begin{array}{l}\text { \# of hypertension visits for the sample } \\
(\mathrm{n}=1661)\end{array}$ & $9,135.50$ & 8305 & 9966 \\
\hline Cost per GCCN visit & $\$ 75$ & $\$ 68$ & $\$ 88$ \\
\hline Total GCCN Expenditures & $\$ 685,163$ & $\$ 564,740$ & $\$ 877,008$ \\
\hline NET BENEFITS (Savings - Expenditures) & $\$ 407,783$ & $\$ 1,082,667$ & $-\$ 321,527$ \\
\hline BENEFIT-COST RATIO (Savings/Expenditures) & 1.6 & 2.9 & 0.63 \\
\hline
\end{tabular}




\section{DISCUSSION}

Management of hypertension in GCCN clinics indicates a good investment in the base-case and the best-case scenarios, based on the results of the cost-savings calculations shown in Table 3. Considering a hypothetical cohort of 100 patients receiving hypertension treatment in GCCN clinics over the course of a year, the estimate is that $\$ 13,500$ and $\$ 5,700$ will be saved from reductions in CHD events and stroke, respectively, and $\$ 46,600$ will be saved due to fewer ED visits. When adjusted for the annual expenditures to treat 100 patients annually in GCCN clinics $(\$ 41,250)$, the estimate is that for each $\$ 1$ spent by GCCN clinics, there is an average savings of $\$ 1.60$. This represents an annual savings of roughly $\$ 24,500$ for each 100 patients screened and treated for hypertension in GCCN clinics.

Although the worst-case scenario does not produce a favorable ROI, the economic returns are positive when key model inputs are varied one at a time, rather than simultaneously. Further, in comparison with other screening and treatment options for hypertensive patients, the GCCN may still represent a cost-effective option for managing hypertension in the uninsured population. Prevention costs money, and the money spent on prevention may well be worth the money spent on treatment in the long-term.

\section{Limitations}

There are three major limitations to this analysis. First, we used a healthcare system perspective, which is limited to costs to the clinic and other healthcare providers. The analysis does not include the costs of medications required to manage hypertension, and, although these are not costs that are realized by GCCN clinics, medications represent a cost to some part of the healthcare system (even if they are overstock and provided for "free" or reduced prices). From a societal perspective, the costs of medications would have been included, even if they were free to hypertension patients frequenting GCCN clinics. Costs to patients would also be included in the societal perspective, including any healthcare costs paid out-of-pocket and losses in productivity associated with CHD and stroke events. Second, since incidence rates for CHD events and stroke in Georgia were not available, Georgia hospital discharge and death rates were used. These were from the OASIS data based on categories of disease that do not perfectly align with the CHD definitions provided in Law et al. (2009) and Song et al. (2013). The incidences of CHD and stroke are likely higher in the South; however, the present estimates, which are lower than those used by Song et al. (2013), do not reflect that knowledge. Consequently, the estimates of CHD and stroke events averted are likely to be conservative.

Third, all costs related to the initial identification of the cohort of 1661 hypertensive patients were not included, as each clinic likely served multiple patrons per hypertension case identified. Since patient-level data were not available for the entire clinic population, the analysis of costs and benefits was limited to the treatment of the 1661 patients. Given the small number of clinics providing patient-level data $(n=12)$, it is also possible that these sites are not a representative sample of all GCCN clinics and may manage patients more or less efficiently than others in the network.

\section{Implications for Public Health}

Based on results of these analyses, there is economic evidence to support investment in GCCN clinics across the state for the screening and treatment of hypertensive patients. Further, it is likely that the management of other chronic conditions in GCCN clinics would provide similar economic returns. For example, Fertig et al. (2012) conducted a case study in which they estimated the benefits and costs of a free clinic in Georgia providing general primary care services. By use of matched data from the clinic and its corresponding regional hospital on a sample of newly enrolled clinic patients, the authors found that patients' non-urgent ED and inpatient costs at the hospital fell by $\$ 170$ per patient in the year following clinic enrollment. After 3 years of sustained clinical management of chronic diseases, they estimated that the savings from reduced hospital utilization would offset clinic expenditures. In another study, Zhou et al. (2014) found that among a group of indigenous residents of Australia, primary care for renal disease and diabetes was the most cost-effective investment of clinical services, followed by hypertension and ischemic heart disease.

Despite the demonstrated positive ROI for screening and treating hypertension in GCCN clinics and the likelihood of greater economic impact from comprehensive GCCN services, the network's current patient capacity represents only a small fraction of the uninsured. In 2013, 23\% of Georgians were uninsured, but GCCN clinics served only 8.5\% of this population (Kaiser Family Foundation, 2014). An efficient use of state resources may be to fund these clinics in order to expand the population served and consequently reduce uncompensated care costs for chronic disease management and avoidable ED visits.

Although increased funding is essential to reach these goals, expanding the reach of free and charitable clinics in Georgia will necessitate more than financial support. First, an efficient and directed expansion will require collection and analysis of high-quality data including descriptions of the demographics, clinical profiles, and health needs of the patient population. Second, improvements in technology and infrastructure may be needed to boost the care capacity of existing clinics. Finally, expansion will require volunteer hours from additional medical and administrative personnel needed to staff these clinics. Addressing these hurdles and extending the reach of GCCN clinics has the potential to provide cost-savings to the health system through costefficient identification, treatment, and management of chronic diseases and to reduce the adverse health outcomes associated with being uninsured for Georgia's vulnerable populations.

Many of the uninsured suffer from chronic diseases requiring regular monitoring and comprehensive treatment, and local clinics strive to meet these health needs. Clinics 
also offer preventive services and patient education to a high-risk population lacking access to affordable primary care. In states forgoing Medicaid expansion, free and charitable clinics will continue to make up an important part of the healthcare safety net, and providing these clinics with sufficient resources for comprehensive disease management is a more efficient and compassionate use of funds than treating chronic disease crises in EDs or not at all.

\section{Acknowledgement}

This study was supported by a grant from the HealthCare Georgia Foundation and was approved by the Institutional Review Board at the University of Georgia. We acknowledge the leadership and generosity of Donna Looper, Director of the Georgia Charitable Care Network (GCCN), for coordinating the data collection efforts with the participating charitable and free clinics that affiliate with GCCN.

\section{References}

Bailey, A. (2013, March 25). Misuse of emergency rooms: A costly but avoidable error. Georgia Health News. Retrieved from http://www.georgiahealthnews.com/2013/03/misuseemergency-rooms-costly-avoidable-error/

Bicki, A., Silva, A., Joseph, V., Handoko, R., Rico, S. V., Burns, J., . . De Groot, A. S. (2013). A nurse-run walk-in clinic: Costeffective alternative to non-urgent emergency department use by the uninsured. J Community Health, 38(6), 1042-1049. doi:10.1007/s10900-013-9712-y

Fertig, A. R., Corso, P.S., \& Balasubramaniam, D. (2012). Benefits and costs of a free community-based primary care clinic. $J$ Health Hum Serv Adm, 34(4), 456-470.

Georgia Department of Public Health, Office of Health Indicators for Planning (OHIP). (2015). Online Analytical Statistical Information System (OASIS), Mortality/Morbidity Web Query Tool -- 2013 [data set]. Retrieved from http://oasis.state.ga.us/
Kaiser Family Foundation. (2014). Health Insurance Coverage of Adults 19-64 - 2013 [data set]. Retrieved from http://www.kff.org/other/state-indicator/adults-19-64/

Law, M. R., Morris, J. K., \& Wald, N. J. (2009). Use of blood pressure lowering drugs in the prevention of cardiovascular disease: Meta-analysis of 147 randomised trials in the context of expectations from prospective epidemiological studies. $B M J$, 338 , b1665.

Machlin, S., \& Chowdhury, S. (March 2011). Expenses and characteristics of physician visits in different ambulatory care settings, 2008 (Statistical Brief \#318) [pdf document]. Agency for Healthcare Research and Quality. Retrieved from http://www.meps.ahrq.gov/mepsweb/data_files/publications/st3 18/stat318.pdf

Moran, A. E., Odden, M. C., Thanataveerat, A., Tzong, K. Y., Rasmussen, P. W., Guzman, D., . . Goldman, L. (2015). Costeffectiveness of hypertension therapy according to 2014 guidelines. N Engl J Med, 372(5), 447-455. doi:10.1056/NEJMsa1406751

Nadkarni, M. M., \& Philbrick, J. T. (2003). Free clinics and the uninsured: The increasing demands of chronic illness. $J$ Health Care Poor Underserv, 14(2), 165-174.

Song, Z., Hill, C., Bennet, J., Vavasis, A., \& Oriol, N. E. (2013). Mobile clinic in Massachusetts associated with cost savings from lowering blood pressure and emergency department use. Health Aff (Millwood), 32(1), 36-44. doi:10.1377/hlthaff.2011.1392

United States Department of Labor. (2014). Consumer Price Index. Bureau of Labor Statistics. Retrieved from http://www.bls.gov/cpi/

Weinstein, M. C., Coxson, P. G., Williams, L. W., Pass, T. M., Stason, W. B., \& Goldman, L. (1987). Forecasting coronary heart disease incidence, mortality, and cost: The Coronary Heart Disease Policy Model. Am J Public Health, 77(11), 1417-1426.

Zhao, Y., Thomas, S.L., Guthridge, S.L., \& Wakerman, J. (2014). The cost-effectiveness of primary care for Indigenous Australians with diabetes living in remote Northern Territory communities. Med J Aust, 200(11), 658-662. 